\title{
Getting Active In The Classroom
}

Tanya Yerigan, Southwest Minnesota State University

\begin{abstract}
This paper presents active learning theory and how implementation of dynamic instruction strategies can transform the K-12 classroom. A multi-part study was conducted to determine both the level of active learning knowledge among participants and applicability of newly acquired approaches within the participants' classrooms. First, teachers were surveyed regarding their knowledge of active learning; second, they were educated on the concept and trained in methods; third, participating instructors implemented active learning techniques; and, fourth, participants were surveyed after conducting a minimal number (one active learning activity a week for six weeks) of lessons that integrated active learning theory. The goals of this study were to assess the level of readiness of the K-12 teacher to implement active learning, educate them on active learning, have them utilize active learning principles and share the results.
\end{abstract}

\section{DEFINITION}

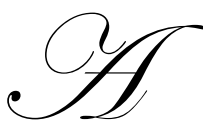

one another, or dyads, or in small or large groups.

\section{PURPOSE}

In education today, there are many terms that are similar or synonymous with active learning, including cooperative learning, hands-on learning and experiential learning. The purpose of this research is to introduce the concept of active learning, share relevant research and delineate options for implementing specific techniques in the classroom. Although this research addresses the K-12 classroom, active learning can be utilized at any academic level.

\section{BACKGROUND}

Although much literature exists on implementing active learning in K-12 and post-secondary educational systems, the focus of this research will be on active learning in the K-12 setting. Whether K-12 or beyond, with simple modifications the principles are applicable to any setting, regardless of age or grade level.

There is much to say about memory and how information is retained. Most educators have heard that people generally remember $10 \%$ of what they read, $20 \%$ of what they hear, $30 \%$ of what they see, $50 \%$ of what they hear and see, and $90 \%$ of what they teach. If this is true, educators should be making a shift to utilizing teaching strategies that promote engaging students in reading, hearing, seeing and teaching--especially, teaching. When using active learning strategies (when the students become the teachers) it is this researcher's assertion that the majority of students will be engaged and participating in discovery in the classroom. Perhaps it may be much closer to $100 \%$ of the students who are contributing to the learning environment. Imagine having the majority of students connecting to the material and lesson in a classroom! According to Silberman (1998), when learning is active, the student are doing most of the work; and their brains are studying ideas, solving problems and applying what they are learning. Often the students are up and out of their seats, collaborating with others, thinking aloud and doing most of the work. The teacher becomes a facilitator of the student's learning and the focus shifts from teaching to learning. 


\section{METHODS}

Introduction of the active learning concept took place in a three-hour seminar located in a neutral and professional setting outside of the participants' school districts. To test the active learning theory, 20 practicing K-12 teachers were introduced to the concept of active learning. Actual active learning techniques were utilized to demonstrate the strategies and train the teachers. Five popular active learning strategies were randomly selected for use in this study. The five strategies include One-Minute Paper, Jig Saw, Di-scussions, Casual Answer Tool and Think-Pair-Share. Participating teachers were asked to incorporate a minimum of one active learning strategy into their curriculum each week, for six-weeks. Teacher participants were cautioned that active learning was not a replacement for lecture or other methods of content delivery; it was to be implemented as a supplement and should be used as an enhancement of and reinforcement for learning. As a result of this study, 420 students were introduced to the active learning concept. Data collected included teachers' prior knowledge of active learning, reflective journals from teachers, student grades and student participation.

\section{IMPLEMENTING ACTIVE LEARNING STRATEGIES}

There are many active learning activities that can be easily implemented into a teacher's curriculum. To incorporate active learning, the instructor does not have to abandon his or her current teaching method. One simply needs to add a few strategically implemented activities. McKeachie (1986) cites a study indicating that immediately after a lecture, students recall $70 \%$ of the information presented in the first ten minutes and only $20 \%$ of that from the last ten minutes. Since the most popular instructional method is currently lecture, it would make sense that, after 10 or 15 minutes of lecture, other learning strategies be integrated into the lesson design. Perhaps integration of a short active learning activity 15 minutes into class would be ideal. Active learning strategies can last anywhere from five minutes to several hours. It is often written that this is what makes the strategies so palatable. They can be adapted for any amount of time, size of group, age of student, setting or topic.

When implementing active learning strategies, there are a few accountability factors to consider. First, as the activity is taking place, the teacher should always float around the room, stopping in on groups. With the students aware that the teacher might participate in the group, the students nearly always stay on task. If the teacher does choose to sit in a group, this should be done not as an expert contributor but as an equal learner. Teachers know information so well because they teach the topic. If we want the students to know the material, we must have them teach the material or engage it in some way without us. Second, students should always return to the large group after an activity. This will assist with ensuring that the students complete their assignment. Since students are sometimes allowed to work in the hall or other available areas outside of the classroom during active learning, it will further ensure that the students will return. Finally, teachers need to be aware that since active learning is just that, "active", the volume in the classroom may elevate. This is normal and should be expected.

\section{ACTIVE LEARNING STRATEGIES}

The active learning strategies selected for this study have been collected, exchanged, modified and collaborated upon over the course of this researcher's career. Some come from conferences or workshops; others were developed departmentally or individually; and still others are adapted and customized blends of techniques that other experts recommend. Since these activities have been collected from multiple sources over several years, the original source of some is unknown. Although there are several variations for some of these activities, these are the adaptations that have worked best in the researcher's classrooms, whether K-12 or higher education. The participating educators were allowed to select from the following active learning strategies.

\section{One-Minute Paper}

No other technique has been used more often or by more teachers than the One-Minute Paper. This active learning strategy provides a quick and simple way to collect written feedback on student learning. To use the OneMinute Paper, the teacher stops class two or three minutes early and asks students to respond briefly to a question or two. Examples might include "What was the most important thing you learned during this class?" and "What would 
you like to learn about the topic?" Students are then given the time to write their responses on a piece of paper and hand them in. The following is the step-by-step process for implementing the active learning strategy, One-Minute

\section{Paper:}

1. Decide first what you want to focus on and when to administer the One-Minute Paper. If you want to focus on students' understanding of a lecture, the last few minutes of class may be the best time. If your focus is on a prior homework assignment, the first few minutes may be more appropriate.

2. Using the two basic questions above as starting points, you can write One-Minute Paper questions that meet your needs.

3. Plan to set aside five minutes of time to use the technique, as well as time later to discuss the results.

4. Before class, write one or two One-Minute Paper questions on the chalkboard; have them preprinted; or prepare an overhead transparency.

5. For this technique, hand out the preprinted set of questions, index cards or half-sheets of scrap paper.

6. Unless there is a good reason to know who wrote what or the paper is going to be used as an assessment tool, direct students to leave their names off the papers or cards.

7. Let the students know how much time they will have (one to two minutes per question is usually enough), what kinds of answers you want (words, phrases, or short sentences), and what you will be doing with the information they provide.

\section{The Jig Saw}

There are several purposes for which one may utilize the Jig Saw strategy. However, the three main purposes are to provide an alternative to lecturing and reading, to create interdependence among group members and to ensure oral rehearsal and cognitive elaboration of the material studied. This strategy includes learning and becoming an expert on the material, planning how to teach it to others, teaching your section to others and checking for understanding. The following is the step-by-step process for implementing the active learning strategy, Jig Saw:

1. Divide participants into groups or pairs depending on number of participants and number of different reading selections.

2. Assign a different article or part of reading material, such as a book chapter, to each group or pair.

3. Groups or pairs may assign a portion of the reading material to each member in the group to cover longer reading assignments quickly. (ie: Ten pages-each reads two for a group of five)

4. Each member is responsible for creating a clear synopsis of his or her portion of the reading material. It is recommended that the student write down one to five key points from the reading.

5. The pair or group prepares a presentation, which covers the information presented by each member of the group.

a. Choose key points and identify

b. Be creative and use notes, visual aids, pictures, active involvement or own experiences

c. Check for clarity and understanding among group members

d. Presentations should be limited to no more than five minutes each

6. Small groups present to the whole group

7. Discussion (Variable)

a. The teacher randomly selects individuals to answer questions or comments on the sections they did not teach

b. The teacher or any student can add comments and ideas to the discussion

There are several variations that can be utilized for this technique. This is not a comprehensive list of variations. The possibilities are limited only by the instructor's imagination.

1. Divide the students into groups. Assign each member of the group a different article or section to read and to prepare a brief synopsis to share. 
2. All students who read the same material will get together and share their summaries and reach agreement on the material which will be presented.

3. All members return to their original group and present the shared summaries. No large group presentations are necessary.

\section{Di-scussions}

Di-scussions is an active learning strategy that can be used to look at a topic from many different angles. Using Di-scussions can help the students to dissect a topic and attain higher-level thinking/learning while playing a game. The following is the step-by-step process for implementing the active learning strategy, Di-scussions:

1. Divide the class into groups of no more than five to six students.

2. Select a topic to use with the Di-scussions strategy.

3. Roll the dice for a number. The student answers the question below that corresponds to the number. Then others in the group are allowed to give their responses on the question, or they can save their answer and/or opinion in case they roll the number later.

4. Answer each of the six questions by writing down responses. Each group member may record the answers, or one recorder can be used for the group.

5. Answer all six questions first, and then the students may be permitted to play Di-scussions as long as time permits.

The questions below can be utilized with the topic. The number rolled on the dice indicates the question that should be answered. Do not forget to copy a list of the questions for each student or group to have.

Question 1: List two new thoughts you have about this topic that you did not have before the lesson.

Question 2: Ask each player in the group to identify when knowing about this topic may be important.

Question 3: Make a connection between this topic and something else you know about.

Question 4: As a group, list three things you could do to learn more about this topic.

Question 5: If this topic never existed, how might the world be different?

Question 6: List 3 questions you still have about this topic.

There are several variations that can be utilized for this technique. This is not a comprehensive list of variations. Again, the alternatives are limited only by the teacher's inventiveness.

1. Adapt these questions as you wish.

2. Specific questions can be developed and used for chapter or test review.

3. Allow students to develop six topic or review questions. Have them exchange with another group.

\section{Casual Answer Tool}

The Casual Answer Tool (C.A.T.) is a technique this author developed to provide an opening icebreaker, topic summary, content review and mid-course evaluation of student understanding. Select an object to be used as the tool. Items that can be utilized might include but are not limited to a ball or stuffed animal. The specific object that is selected as the C.A.T. serves three purposes. The first purpose is to serve as a talking piece; the person holding the object is the only person who can speak. Second, the object is the selector of the next person to talk. Finally, the object serves as a means to keep the student's mind off of speaking in front of others; it is common for the student to fidget with the C.A.T. while responding to the question. The following is the general step-by-step process for implementing the active learning strategy, Casual Answer Tool. Additionally, there are several variations that can be used.

1. Arrange the Students. Students may remain in their seats or can be arranged in a circle (standing or seated).

2. Topic/Question Selection. A topic or question is selected. Students answer when the C.A.T. is randomly tossed to them. 
There are several variations that can be utilized for this technique. This is not a comprehensive list of variations. The possibilities are limited only by the instructor's ingenuity.

1. C.A.T can be used as an icebreaker. When used as an opening icebreaker, the teacher may want to ask general questions that are intended to help the students get to know each other, alleviate stress or determine expectations of the course. Some examples may include "what are you hoping to get out of this course?" "What is your favorite aspect of this course?" "What is your favorite television movie and why?"

2. The C.A.T. may be used as a summary or check for student understanding. When used as a summary or check for student understanding, you may want to utilize questions such as "what did you learn that you didn't know before?" "What would you like to learn more about?" "What questions do you still have that remain after today's lesson?"

3. The C.A.T. may be used for content review. When used as a content review, you can generate one specific question for each student to add to; or you can start with one question and, after it is answered, the student with the C.A.T. makes up a new content question for the next person who is tossed the C.A.T. The same question is repeated until it is answered satisfactorily. This can be used for chapter review or test review.

\section{Think-Pair-Share}

The Think-Pair-Share is an active learning strategy that provides processing time for 10:2 theory, builds in wait time, provides rehearsal, enhances depth and breadth of thinking, increases level of participation, allows the instructor to check for understanding and provides time for instructor to make instructional decisions. The following is the step-by-step process for implementing the active learning strategy, Think-Pair-Share:

1. Ask a question

2. Ask students to think quietly about possible answers to the question; this is usually only thirty seconds to one minute. (Think)

3. Have students join with a partner to discuss their thinking. The discussion usually lasts only two to three minutes. (Pair)

4. Ask students to share with the whole group or with a table group. Not all students share their answers with the large group. (Share)

There are several variations that can be utilized for this technique. This is not a comprehensive

list of variations. The options, of course, are limited only by the teacher's creativeness. Times to use the Think-PairShare may include the following:

1. During class discussion so that all students have the opportunity to participate.

2. During those times when you want to give a great deal of information to the class with a minimum amount of lecture.

3. To provide opportunities for clarification after a new topic or concept has been introduced.

4. During a film or lecture, stop every 10 minutes to have students think about key points. Then allow two minutes for them to share with a partner. (10:2 Theory)

\section{GENERAL FINDINGS}

\section{Teacher Reflection Journals}

Overall, the participating teachers reported that, for their students, the strategies seemed to provide an emotional connection, link the topic to prior knowledge, make sense/provide personal relevance, provide for individual/group reflection, reduce stress and provide for alternative ways to assess knowledge. On a negative note, the participants found that if the active learning strategy was not well thought out, it was still fun for the students but did not promote much learning. They cautioned that time must be taken to incorporate these strategies into the curriculum in a quality manner. 


\section{Student Grades}

In general, the teachers found that during the lessons where active learning strategies were implemented, the student grades increased by an average of $12 \%$. Over $75 \%$ of all students increased their grades in at least one subject area. Additionally, the students' long-term comprehension of the topics presented with active learning techniques appeared to improve.

These findings are supported by data taken from minuteman.org (2005), which demonstrates that students who learn in traditional ways such as homework and lecture have traditional (normal curve) results, with a few students receiving A's and F's and most scoring in the middle. However, when brain-compatible strategies such as active learning are implemented, student learning is accelerated. There is much higher achievement with less variation (more A's and B's and fewer C's, D's and F's).

\section{Student Participation}

The teachers reported that student participation increased an average of $75 \%$. Additionally, students who were previously content with minimal peer interaction dramatically increased their interactions. On the reverse, students who previously had good participation maintained a high degree of interaction and yielded a slight increase. A much smaller number of students $(5 \%)$ had difficulty adjusting from the traditional lecture format to a more interactive classroom and decreased their interactions.

\section{CONCLUSIONS}

The main teacher-reported drawback of active learning was the need to structure the activities to avoid disruptive behaviors (yelling, running around, leaving class and being off-task). Sixty percent of the teachers reported that planning lessons which incorporated active learning and the necessary structure, increased their preparation time by an average of 15 minutes per lesson. This was an average increase of $50 \%$. Overall, $90 \%$ of participating teachers reported that implementation of active learning strategies was beneficial but time-intensive. Sixty-five percent of the teachers reported that due to student successes, they would continue to implement active learning strategies on a weekly basis.

For the majority of the students, the strategies seemed to provide an emotional connection, linked topics to prior learning, had personal relevance, provided for individual/group reflection, reduced stress, increased peer interactions and provided for alternative ways to assess knowledge. Finally, the majority of students realized an increase in grades and comprehension.

The data collected in this study indicate strong support for the implementation of active learning strategies into the K-12 classroom. According to this study, neither demographics nor student grade-level seemed to significantly impact the findings. It is clear that active learning strategies increased student interaction with their peers, promoted a higher level of thinking and increased grades at all K-12 grade levels.

\section{REFERENCES}

1. Berk, R., (2003). Professors Are From Mars, Students Are From Snickers. Sterling, VA: Stylus Publishing

2. $\quad$ McKeachie, W.J., (1986). Teaching Tips, 8th Edn. Lexington, MA, D.C: Heath \& Co.

3. Minute Man.Org. (2005). Retrieved February 25, 2005, from Minute Man: http://www.minuteman.org/topics/card1.html

4. Silberman, M. (1998). Active Training: A Handbook of Techniques, Designs, Case Examples, and Tips. Indianapolis, IN: Wiley, John \& Sons. 